\title{
STUDIES ON MOTOR METAMERISATION OF THE UPPER AND LOWER LIMBS
}

\author{
By \\ A. Grossiord and J. Buzacoux \\ Raymond Poincaré Hospital, Garches, France \\ and \\ M. Maury and G. Barthes \\ Centre de Reéducation Motrice, Fontainebleau, France
}

\section{INTRODUCTION}

MANY aspects concerning motor metamerisation are still unsolved. Accurate anatomo-clinical studies are scanty, and a comparison of charts on segmental innervation, which appear here and there in the literature, reveals surprising divergences. Moreover, tackling this problem is not easy, as to the inevitable uncertainties of methods must be added unexpected individual variations in the anatomical arrangement.

Ignoring preconceived ideas and theories, usually too strict to be quite convincing, we have pondered about this problem. Enlightened by the everyday study of the para- and tetraplegic motor semeiology we have tried, by a comparative study of many muscle tests, to define as accurately as possible the relative topography of the upper levels of the various motor nuclei of the spinal cord.

We expected, of course, to meet with classic conceptions, but this systematic study leading to anatomical conclusions by the clinical method seemed to us to be worth while trying.

The analysis of the pathological data, being less arduous for the roots than for the spinal cord, showed the motor systematisation of the anterior roots to be the most instructive one.

From the first intuitions of Duchenne de Boulogne (1867) and the description of the upper and lower radicular types of brachial plexus by Erb (1874-quoted by Grasset 1894) and Mme Dejerine-Klumpke (I885-quoted by Grasset), the following sources have enlarged our topographical knowledge: the experiments of physiologists such as Ferrier (I88I), Paul Bert (I883), Sherrington (I892), to quote only the leading ones, the anatomo-clinical data collected by Dejerine and his successors (1914-26), the anatomical studies of Villiger and Ludwig (1946), and more recently, the work of the Medical Research Council (M.R.C.) (I960) on the traumatic pathology of plexuses and roots, many observations of neurosurgeons (Foerster, 1929, 1936) on radicular compressions or sections and some elaborate electro-clinical studies (Gronemeyer-quoted by Morin 1948, Schliack, 1957). However, there are still imperfections concerning details, which are of importance in neurological semeiology.

The first studies on motor nuclear systematisation were concerned with amputees who had undergone more or less extensive mutilations. The problem 
in question was whether the histological investigation of the spinal cord would show up chromatological images systematised enough in certain areas of the anterior horns. Sano, as early as I897, thought he could state positively that each muscle of the limbs has its own spinal cord nucleus, just as the cephalic motor formations have their own one in the lower brain stem. This statement was shaken by experimental investigations made after nerve sections and amputations on animals by Marinesco (quoted by Dejerine I9I4-26) Parhon et Popesco (quoted by Dejerine), also by Van Gehuchten and De Neef (1900). However, Bruce (I90I), also experimenting on recently amputated subjects, came to the same conclusions as Sano that each motor spinal nucleus lies on a rather important height, two segments at least, which was consistent with the data of the experimental physiology of the motor roots. Dejerine agreed with these spinal localisations but thought it only reflected the radicular topography.

These studies, though founded on histological images and perhaps not conclusive enough, were already of great value. But it was not until many years later that other studies could bring further data which were really accurate: the studies of Romanes (I94I, I946, I953) and, in particular, the contribution of Sharrard (1955), who, starting from anatomo-clinical data on polio patients, could lay down a topographical map of the motor spinal nuclei of the lower limb and define the approximate level of these nuclei.

The spinal motor nuclei are of very unequal length, as Sharrard showed very clearly. A short nucleus and in a right position in front of the emergence of an anterior root can possibly use only one root, and this is perhaps the case in some muscles, such as extensor hallucis longus and peroneus brevis (Schliack, 1957) although this is not agreed by all authors. But it will be different if the nucleus is longer or partly on each of two radicular exits. There are certainly many problematical and individual factors in these topographies which may account for the uncertainties which are left and which we cannot pretend to remove entirely.

The same must be said from the functional point of view. Van Gehuchten's 'Theorie segmentaire' of an antebrachial nucleus, a brachial nucleus, etc. (I898, I900), has been strongly criticised and it cannot be accepted in such an oversimplified form. Paul Bert (I883) thought that every root innervates only synergic muscles and Ferrier (I88I) believed that the roots have co-ordinated functions. In our opinion, this is setting too high a value upon roots. Each root puts into action very different muscles; therefore the concept of synergy is open to criticism. The tibialis anterior often works in synergy with tibialis posterior, but it may also act as an antagonist. There is nothing simple in neurophysiology. It is true that the dominant function of a root sometimes allows one to define, as our colleague Benassy (1963) did, a distinct scheme, but we think such conclusions must not be too categorical, especially when the muscle in question has a long nucleus, which can indeed control various bundles of this muscle.

\section{METHOD OF PROCEDURE}

This comprehensive study is concerned with analysing the muscular tests of patients with stabilised spinal cord lesions of traumatic origin occurring at various levels. In order to make such records meaningful within the scope of the present study, we considered only those cases where the upper level of the lesion was localised with a fair degree of accuracy. On a series of records it was thus possible 
to see the sequence in which new muscle performances appeared, as the level of lesion became lower and lower down the cord.

The muscular testing charts utilised here are found in the medical records of all our patients: they record the results of tests carried out regularly (every three months, on the average) by experienced physicians and physiotherapists, using well-established techniques and a grading scale of muscular action ranging from 0 to 5. All the grades do not have the same significance; whereas a muscle, graded at 3 is fairly strong, a muscle graded 2 is very weak and this figure already indicates a highly significant deficit. But when in a column where only zeros are listed, muscles are seen appearing with I or 2 grades and especially when such an irregularity occurs a certain number of times, we may conclude that this fact is not unrelated to the respective locations of the upper levels of the relevant muscles. In order to minimise the chances of error and not clutter up the tables, some muscles were left out, either because they are difficult to test accurately $(e . g$. the rotators of the hip) or because they are of lesser importance (rhomboids). We should also mention that the muscle grading scale was used in two slightly different ways. For the lower extremities we used 0 to 4 grades only (grade 4 and grade 5 being equated) and reduced the more specific notations $\left(\mathrm{I}+, 3_{-}\right)$to the simple numbers, whereas the whole system of notations (grades and plus or minus signs) was kept for the upper extremities.

The first step was to fill out a form with the information provided by each case selected. Among other data, the sensory level and the muscle gradings were entered. In comparing the motor and sensory levels again we became aware of the large number of cases with an area of hypo-aesthesia existing at the upper level of the lesion. We also detected some differences between the two levels (the sensory level being generally lower and sometimes a great deal lower) and also some dissociations, with losses in temperature appreciation usually appearing at the highest level. These records were filed with the lesions arranged in a downward sequence; then in a second stage, all the muscle gradings were gathered into a single chart where each column corresponds to an extremity and each line to a muscle. The extremities are thus arranged according to the succession of the lesional levels down the cord, and the muscles according to the sequence assumed to be the actual one. If this sequence was accurate, the positive grades would appear in orderly succession as the level of the lesion became lower and lower.

The investigations were carried out jointly by the Hôpital Raymond Poincaré at Garches and the Centre de Reéducation Motrice at Fontainebleau and the results of the two research projects were compared at regular intervals. The lower extremities were studied more specially at Garches, and the upper extremities at Fontainebleau. Although we may find some slight differences in the presentation of the results, they reflect the common approach which existed between the two institutions.

Lower Limb. Forty-eight lower limbs have been analysed, corresponding to 24 patients answering the above-mentioned conditions; the notion of 'zero lower segment' is, however, a little hazier for some of the lowest lesions of our study.

Figure 2 gives for each limb the main sensory-motor topographical characteristics. In order not to overweight them, these tests have been somewhat schematised, the sensory level having only an indicative meaning for the abovementioned reasons. The order in which muscles appear on this table corresponds 
approximately to the information given by the British Medical Research Council, as for the radicular origins of the chief muscles in the lower limbs (fig. I), the

\begin{tabular}{|c|c|c|c|c|}
\hline lliopsoas & L2 L3 & & & \\
\hline Sartorius & L2 L3 & & & \\
\hline Adductor & L2 L3 & L4 & & \\
\hline Quadriceps & L2 L3 & L4 & & \\
\hline Tibialis Anterior & & L4 & L5 & \\
\hline Tibialis Posterior & & L4 & L5 & \\
\hline Gluteus Medius & & L4 & $\mathbf{L 5}$ & S1 \\
\hline Gluteus Minimus & & L4 & $\mathbf{L 5}$ & S1 \\
\hline Tensor Fasciae Latae & & L4 & $\mathbf{L 5}$ & S1 \\
\hline Semi-T.-Semi-M.-Biceps & & L4 & $\mathbf{L 5}$ & S1 S2 \\
\hline Ext. Dig. Longus & & & $\mathbf{L 5}$ & $\mathrm{S} 1$ \\
\hline Ext. Hall. Longus & & & $\mathbf{L 5}$ & S1 \\
\hline Peronei & & & $\mathbf{L 5}$ & S1 \\
\hline Gluteus Maximus & & & $\mathbf{L 5}$ & $\mathbf{S 1} \mathrm{S2}$ \\
\hline Ext. Dig. Brevis & & & & S1 \\
\hline Triceps & & & & $\mathrm{S} 1 \mathrm{~S} 2$ \\
\hline Flex. Dig. Longus & & & & $\mathrm{S} 1 \mathrm{~S} 2$ \\
\hline Flex. Hall. Longus & & & & $\mathrm{S} 1 \mathrm{S2}$ \\
\hline Flex. Dig. Brevis & & & & S1 S2 \\
\hline Small Muscles of Foot & & & & S1 S2 \\
\hline
\end{tabular}

FIG. I

Motor radicular topographies of lower limbs (British Medical Research Council). The predominant roots are in bold type.

upper root being the only one retained, even if it is not regarded as prevalent in the text of the B.M.R.C. This shows the arbitrary character of the classification. We have chosen it because it seemed to us to be one of the most valid in our possession and because we thought a greater meaning would thus be conferred to the 'blanks' which juxtaposed motor testings would show. Gracilis, about which we will have the opportunity of speaking later, does not appear on this table for it had not been ciphered precisely enough in all observations. So has been the case with the extensor digitorum brevis and the intrinsic muscles of the foot. On the other hand, we have divided 'the hamstrings' because of their considerable topographic interest. We endeavoured, as far as possible, to put on the left of fig. 2 the most severe cases.

The key-muscles, as for the drawing-up of the schematic motor level, as one knows it, are not numerous: Iliopsoas and sartorius, quadriceps, tibialis anterior, extensor digitorum longus, triceps . . . but many gradations may appear in paraplegic pathology and it is not always possible to name the motor level of a distinct case with absolute precision.

In our Figure 2 there are some very high lesions and a good many $\mathrm{L}_{4}$ levels. Unfortunately we have only few very low lesions. 


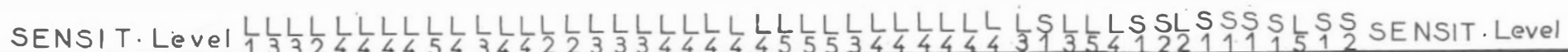

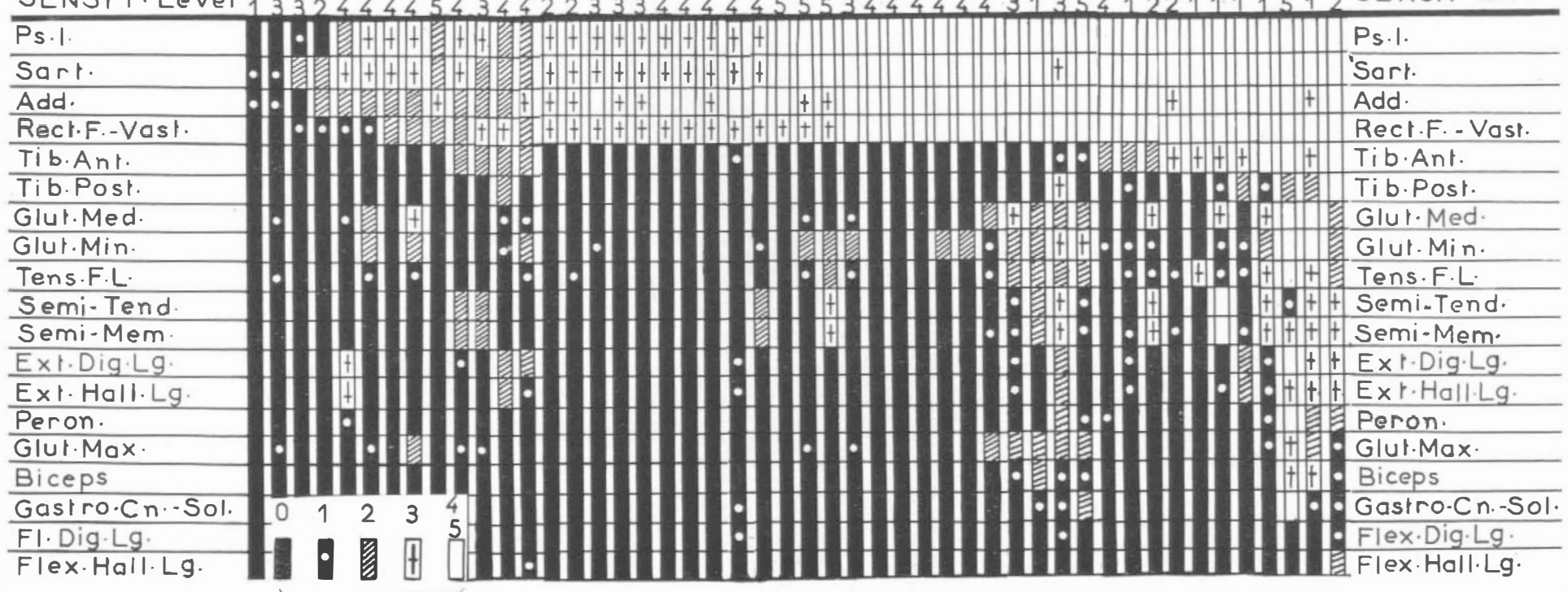

Key

FIG. 2

Schematic sensori-motor tests of 48 lower limbs. Each vertical column corresponds to a limb. Approximate sensory level is indicated at the top of the column. As for motor tests, numbers $0, \mathrm{I}, 2,3,4,5$ only have been retained, middle values being rounded to the next whole number; the order in which the various muscles have been put corresponds exactly to data of 'Medical Research Council'. 
I. Iliopsoas and Sartorius. Contrary to other authors' opinion, sartorius seemed to us to be the first to appear in paraplegia which is not absolutely total. The testing of the psoas muscle is not easy, as the stretching of the tendon on the lesser trochanter may be difficult to appreciate if it is deeply rooted.

2. Quadriceps and Adductors. Rectus femoris on the one hand, pectineus and adductor brevis on the other, seem to have a privileged position; on examination, a paralytic spina bifida case very often shows the quadriceps with vasti 'trace or zero' whereas rectus femoris is quite strong. The dynamometric testing of the strength of the muscle is of great importance when it is ciphered ' 4 ' or more and gives a clearer idea of the proportion of intact motor units and consequently of the extent of the still active spinal nucleus; Maury and Barthes consider that a lower limb whose quadriceps is above $30 \mathrm{~kg}$. strong is quite probably controlled by a normal nucleus. But we must be cautious in our conclusions for, as Sharrard showed (I955), a muscle may be nearly normal with a largely reduced number of motor units.

3. Tibialis Anterior and Tibialis Posterior. The latter seems to us definitely lower than the former. Tibialis posterior very often is zero or very weak, whereas tibialis anterior is quite strong.

4. Glutei. We have often found some motor activity of the glutei even when tibialis anterior was zero. This is especially the case for gluteus minimus and gluteus medius, the upper limit of gluteus minimus being perhaps even a little higher than that of gluteus medius. Gluteus maximus is lower and this is consistent with the general opinion, but it may give slight contraction even in fairly high lesions. Mistakes are, however, possible and some of our cipherings may not be quite exact, because contraction of the posterior fibres of the gluteus medius, or active extension of the hip, due to one of the hamstrings or still more due to action of the adductor magnus, have been the cause of confusion.

5. Tensor Fasciae latae and gluteus medius seem to have a rather similar position, which is in perfect agreement with Sharrard's data.

6. Hamstrings. It seems to us of particular interest to examine these muscles; the poliomyelitis pathology has made us familiar with the 'Biceps-triceps' syndrome (Bennett, I95I). This phenomenon is observed in many paraplegics and one can observe frequently a strong contraction of semi-tendinosus and semi-membranosus whereas biceps is zero or nearly so. Biceps is certainly lower than the other two, which usually share a common level, while semi-membranosus has perhaps a slightly higher level. These two muscles may be weakly active whereas tibialis anterior is zero, but there is ground for assuming that the upper level of the three nuclei are not very different. A very frequent fallacy must be mentioned, namely to mistake gracilis for a semi-tendinosus. It is quite normal to observe a very fine action of the gracilis whereas the hamstrings are zero. The upper level of gracilis is obviously the same as that of most of the adductors. Moreover, it is well known that this muscle also plays a part in the active flexion of the knee.

7. Figure 2 also gives information about muscles which are situated in distal parts of the lower limb, but the number of our cases is not large enough to give a full account of the relationship between peronei and triceps and between triceps and long flexors. The upper level of the extensor digitorum longus is, however, definitely higher than that of biceps, triceps and peronei.

With the help of Figure 2, we attempted to objectify mutual relations of the upper levels of the various muscles by comparing individual muscles. Figure 3 
gives the results of this study of the relationship. Some are conclusive, others are based on too low ciphers.

\begin{tabular}{|c|c|c|c|c|c|c|c|c|c|c|c|}
\hline & & $A$ & $B$ & $C$ & & & & $A$ & $B$ & $C$ & \\
\hline SARTORIUS & ILIOPSOAS & 5 & 17 & 2 & & $\frac{1}{2}$ MEMB. & $\frac{1}{2}$ TEND. & 5 & I 2 & 0 & \\
\hline ILIOPSOAS & ADDUCT. & IO & 7 & IO & & $\frac{1}{2}$ MEMB. & GLUT. MAX. & I4 & 3 & 5 & + \\
\hline ILIOPSOAS & QUADRICEPS & 8 & I4 & 2 & & MEMB. & TIB. POST. & I4 & 2 & 3 & ++ \\
\hline ADDUCT & QUADRICEPS & I3 & 10 & 5 & & MEMB. & EXT. DGT. LG. & 12 & 4 & 6 & \\
\hline QUADRICEPS & TIB. ANT. & 35 & 3 & 0 & ++ & MEMB. & BICEPS & I3 & 5 & 0 & \\
\hline TIB. ANT. & GLUT. MIN. & I3 & I & I5 & & $\frac{1}{2}$ TEND. & TIB. POST. & I I & I & 5 & \\
\hline TIB. ANT. & GLUT. MED. & I 2 & I & I 3 & & $\frac{1}{2}$ TEND. & BICEPS & I3 & 5 & 0 & + \\
\hline TIB. ANT. & $\frac{1}{2}$ MEMB. & I 2 & 3 & 8 & & GLUT. MAX. & EXT. DGT. LG. & IO & 3 & 9 & \\
\hline TIB. ANT. & $\frac{1}{2}$ TEND. & I I & 4 & 7 & & GLUT. MAX. & TIB. POST. & I 2 & 2 & 6 & \\
\hline TIB. ANT. & GLUT. MAX. & I6 & 0 & IO & + & GLUT. MAX. & PERON. & I I & 3 & 4 & + \\
\hline TIB. ANT. & BICEPS & I6 & I & 2 & ++ & EXT. DGT. LG. & TIB. POST. & 7 & 4 & 3 & \\
\hline TIB. ANT. & EXT. DGT. LG. & 12 & 4 & 3 & + & EXT. DGT. LG. & BICEPS & I I & 3 & I & + \\
\hline TIB. ANT. & TRICEPS & I 4 & 4 & 2 & ++ & EXT. DGT. LG. & PERON. & IO & 2 & I & \\
\hline TIB. ANT. & TIB. POST. & I 5 & I & I & ++ & EXT. DGT. LG. & TRICEPS & I I & I & 2 & ++ \\
\hline GLUT. MIN. & GLUT. MED. & I3 & 4 & 8 & & TIB. POST. & PERON. & 7 & 2 & 4 & \\
\hline GLUT. MIN. & GLUT. MAX. & $2 \mathrm{I}$ & 3 & 4 & ++ & TIB. POST. & BICEPS & 7 & 0 & 5 & \\
\hline GLUT. MED. & $\frac{1}{2}$ MEMB. & I3 & 3 & 8 & & TIB. POST. & TRICEPS & 8 & 0 & 4 & \\
\hline GLUT. MED. & $\frac{1}{2}$ TEND. & I3 & 3 & 6 & & PERON. & BICEPS & 6 & I & 3 & \\
\hline GLUT. MED. & GLUT. MAX. & 12 & 7 & 2 & + & PERON. & TRICEPS & 6 & 0 & 3 & \\
\hline GLUT. MED. & TIB. POST. & I6 & o & 5 & + & BICEPS & TRICEPS & 3 & 2 & 2 & \\
\hline & & & & & & TRICEPS & FLEX. DGT. LG. & 6 & 0 & 2 & + \\
\hline
\end{tabular}

FIG. 3

Motor correlations (study made according to Figure 2). A number of muscle couples has been analysed. For each couple three ciphers:

$(A)$ cases when the first muscle is the stronger one;

$(B)$ cases when they are equal;

(C) cases when the second muscle is the stronger one.

The cases in which both muscles are 0 or 4,5 have been left out. The most significant correlations have been marked with + or ++ .

Figure 4 shows our conclusions of the succession of the upper levels. The table is self-explanatory.

Upper Limb. Out of 55 cases of tetraplegia which came under our investigation, 40 upper extremities were selected following the criteria mentioned earlier.

An examination of the cases determined which cord segment should be investigated: for the uppermost lesion, corresponding to the most impaired upper limb, all the muscles tested were at zero. For the most distal lesion corresponding to the least impaired upper limb, only the opponens was at zero. Such limits are generally believed to correspond to cord segment $\mathrm{C}_{5}$ - $\mathrm{TI}_{\mathrm{I}}$, since lesions below $\mathrm{T}_{\mathrm{I}}$ do not affect the upper extremities, while lesions above $\mathrm{C}_{5}$ involve damage to the diaphragm, thus making survival highly problematic.

Before making out a synoptic chart for each case, we had to decide on a classification of the muscles. The arbitrary system that we have been using for several years is drawn to a large extent from the work of Kendall and Kendall (I949) and that of the Medical Research Council (fig. 5), whose methods of approach are for the former statistical and for the latter anatomo-clinical radicular. To the best of our knowledge, there are no anatomo-clinical comparative findings for the cervical spinal cord corresponding to Sharrard's work on the lumbo-sacral spinal cord. 


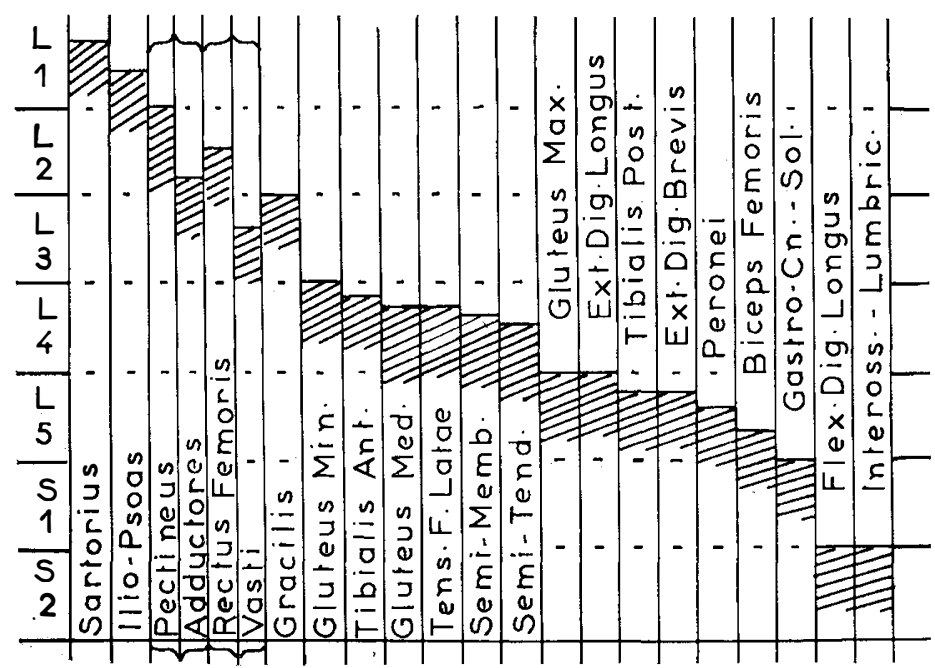

FIg. 4

Upper limits of the various lumbo-sacral myotomes. The segmental references are indicated here in an hypothetical way. The purpose of this chart is to show how, from our experience, the upper levels of the myotomes seem to follow one another in the motor organisation of the spinal cord and lumbo-sacral roots. One will moreover find in the text the reservations we consider necessary for this assumption.

From the outset, a number of muscles had to be left out because they are supplied by fibres arising above $\mathrm{C}_{5}$ (trapezius), or of lesser interest (coracobrachialis, supinator), or too difficult to test, such as the serratus anterior. The hand muscles must be considered separately. Although they are numerous and occasionally difficult to test, we attempted to investigate them separately and to differentiate the different groups, the flexor digitorum profundus from the sublimis. We shall return to this problem later on.

Figure 6 demonstrates all the muscle gradings of the 40 limbs we tested, with each column corresponding to a limb and each line to a muscle. As the limbs were classified according to the level of the injury, proceeding downwards (the first on the left thus belonging to the uppermost lesion, the last on the right to the most distal lesion) and as the muscles were arranged in an order which was assumed tc be the valid one, the positive gradings should, theoretically speaking, have appeared in an orderly sequence as the level of the lesion became lower and lower, that is, as the figure was read from left to right. For instance, when reading the line of the triceps, one can see the value of a change from zero to a positive grade in determining the upper level of its nucleus in relation to the adjacent muscle.

Actually, as soon as we look at Figure 6 and follow the outline of the shaded area, which corresponds to the appearance of each muscle, we realise that certain muscles are not placed correctly. Thus the extensor carpi radialis is obviously placed too low on the list and should be moved above the latissimus dorsi, the internal rotators and the pectoralis major. On the other hand the extensor carpi 
A

\begin{tabular}{|c|c|c|c|}
\hline Deltoid & C5 C6 & & \\
\hline Biceps & C5 C6 & & \\
\hline Ext. Rotators & C5 C6 & & \\
\hline Pect. Major & C5 C6 & C7 & C8 D1 \\
\hline \multicolumn{4}{|l|}{ Int. Rotators } \\
\hline Latissi. Dorsi. & C6 & C7 & C8 \\
\hline Ext. Carp. Rad. & C6 & C7 & \\
\hline Pronators & C6 & $\mathrm{C} 7$ & \\
\hline Ext. Carp. Ulna & & C7 & C8 \\
\hline Triceps & & C7 & C8 \\
\hline Flex. Carp. Rad. & C6 & C7 & $\mathrm{C} 8$ \\
\hline Exten. Digit. & & C7 & C8 \\
\hline Flex. Digit. & & C7 & C8 D1 \\
\hline Flex. Carp. Ulna. & & C7 & C8 \\
\hline Opponens & & & C8 D1 \\
\hline Inter. Lumbric. & & & C8 D1 \\
\hline
\end{tabular}

B

FIG. 5

Motor radicular topographies of upper limb:

$(A)$ according to British Medical Research Council. The predominant roots are in bold type;

$(B)$ according to Kendall (compilation of six authors)

Bold type indicates the selection of three or more authors

Roots in light type mentioned by one or two authors.

ulnaris is placed too high and should be moved two or three lines lower whereas the flexor carpi ulnaris should precede the flexors and extensor digitorum which appear later.

Thus a new classification of the muscles was required and, in order to be precise, it had to be based on a comparison of muscles by groups of two. If, for instance, we wish to determine the respective localisations of the pronator and of the extensor carpi radialis, we shall extract their gradings from the figure (unless both muscles are at zero or 5, which precludes any kind of comparison).

Ext. Carpi. Rad. I - I $2233+3+444+45 \quad 5 \quad 4+5544-4-544+55$ Pronator $\quad \circ \quad 0 \circ \circ \circ \circ \quad 2+0 \circ 3 \quad 33-4-4 \quad 32+3+3+4+4 \quad 4+4$

The gradings of the extensor carpi radialis prevail in 18 cases, those of the pronator in no case; they are equal in two cases (and even there we may observe that the grades are high). Therefore, we felt justified in classifying the extensor carpi radialis before the pronators. Using the same method for all the muscles worth contrasting (fig. 7), we tried to emphasize the reciprocal relationships between the upper levels of the nuclei. Although large numbers are not involved, a majority of the correlations point rather clearly to the prevalence of one nucleus over another but several are still a matter for debate and can serve only as an indication. We shall return to this question immediately after listing our new classifi- 


\begin{tabular}{|c|c|c|c|c|c|c|c|c|c|c|c|c|c|c|c|c|c|c|c|c|c|c|c|c|c|c|c|c|c|c|c|c|c|c|c|c|c|}
\hline & 뭉 & 임 & & & & & & & & & & & $\overbrace{}^{\circ}$ & 品 & ? & 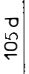 & $\begin{array}{l}\text { ㅁ. } \\
\text { 위 }\end{array}$ & & & 8 & & 员 & & 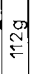 & & & & & & & & & $=\frac{O}{\infty}$ & $\frac{0}{i}$ & $\frac{0}{5}$ & & \\
\hline I to id & & $1+1$ & & 43 & $3+$ & 4 & 4 & 4 & 4 & 4 & 5 & 5 & 5 & 5 & 5 & 4 & 5 & 5 & 4.4 & 5 & 5 & 4 & 5 & 5 & 5 & 5 & 5 & $5 \sqrt{5}$ & 5 & 5 & $5 \longdiv { 5 }$ & 5 & 5 & 5 & 5 & 5 & 5 \\
\hline Biceps & 4 & 3 & 4 & $4+$ & $4+5$ & 5 & 5 & $4-\sqrt{4}$ & $4-$ & 5 & 5 & 5 & 5 & 5 & 5 & 5 & 5 & 54 & $4+4$ & +5 & 5 & 5 & 5 & 5 & 5 & 5 & 5 & 5 : & 5 & 5 & \begin{tabular}{l|l}
5 & 5 \\
\end{tabular} & 5 & 5 & 5 & 5 & & 5 \\
\hline Ext. Rot & 0 & 1 & 3 & 4 & \begin{tabular}{l|l}
4 & 1 \\
\end{tabular} & 1 & 1 & $3 \mid 3$ & 3 & 44 & 4 & 43. & 3 & 4 & 5 & 5 & $4+$ & 53 & $3+3$ & +5 & 5 & 5 & 5 & 5 & 5 & 5 & 5 & 5 & 5 & 5 & \begin{tabular}{l|l}
5 & 5 \\
\end{tabular} & 5 & 5 & 5 & 5 & 5 & 5 \\
\hline Pect. M & 0 & 0 & 0 & 0 & 0 & 0 & 0. & 0 & 0 & $2+4$ & 4 & 4.4 & 3 & $3+$ & 4. & $4+$ & 43 & $3+4$ & 4- 4 & 5 & 5 & $4+$ & 5 & 5 & 3 & 5 & 5 & 5 & 5 & 5 & 54 & +5 & 5 & 5 & 5 & 5 & 5 \\
\hline Int. R & 0 & 1 & $2+$ & 0 & 0 & 0 & 0 & 0 & 0 & 4 & 4 & 43 & $+3+$ & $4+$ & $4+$ & 5 & $3-2$ & 3 & $\begin{array}{ll}4 & 4 \\
\end{array}$ & 5 & 5 & 5 & 5 & 5 & 5 & 5 & 5 & 5 & 5 & 5 & 5 & 5 & 5 & 5 & 5 & 5 & 5 \\
\hline Latissi & 0 & 0. & 0 & 0 & 0 & 0 & 0 & 0 & 0,0 & 0,0 & 1 & 0 & 0 & 0 & 0 & 0 & 0 & 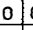 & 0.0 & 1 & $1+$ & 3 & 5 & 4 & 3 & 5 & 5. & 5 & 4 & $4+5$ & 5 & 5 & 5 & 5 & 5 & 4 & 4 \\
\hline Exten.C a r. R oo & 0 & 0 & 0 & $1-$ & 1 & 2 & 2 & 33 & $3+3$ & $3+4$ & 4 & 44 & +4 & 5 & 5 & $4+$ & 5 & $5 \mid 4$ & $4-4$ & 5 & 5 & $4+$ & 5 & 5 & 5 & 5 & 5 & 5 & 5 & $5 \longdiv { 5 }$ & 5 & 5 & 5 & 5 & 5 & 5 & 5 \\
\hline Pronators & 0 & 0 & 0 & 0 & 0 & 0 & 0 & 015 & $0 \sqrt{2}$ & $2+10$ & 0 & 03 & 3 & $3-$ & $4-$ & 4 & 3 & $2+3$ & $3+3$ & +4 & +5 & 4 & 5 & 5 & $4+$ & 5 & 5 & 4 & 5 & 5. & 5 & 5 & 5 & 5 & 5 & 5 & 5 \\
\hline Exte & 0 & 0 & 0 & 0 & 0 & o & 0 & 0 & 0 & 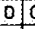 & 0 & 010 & 0 & 0 & 0 & 0 & 0.1 & $0 \longdiv { 5 }$ & 0.0 & 0 & 0 & 0 & 0 & 0 & 0 & 5 & 5 & 2 & 5 & 5 & $5 \quad 5$ & 5 & 5 & 5 & 5 & $4+$ & 5 \\
\hline Trice & 0 & 0 & 0 & 0 & 0. & 0 & 0 & 0 & 0 & 0 & 1 & 10 & 10 & 0 & 0 & 0 & $2+2$ & $2+3$ & $3-3$ & 2. & -3 & $3^{+}$ & 5 & $4+$ & $3^{+}$ & 5 & 5 & 5 & 5 & 5 & \begin{tabular}{l|l}
5 & 5 \\
\end{tabular} & 5 & 5 & 5 & 5 & \begin{tabular}{l|l}
5 & 5 \\
& 2
\end{tabular} & 5 \\
\hline Flexor. Car. Rod. & 0 & 0 & 0 & 0 & 0 & 0 & 0 & 0 & 0 & 0 & 0.0 & 00 & 0 & 0 & 0 & 1 & 0 & 0 & $3 \sqrt[3]{3}$ & \begin{tabular}{l|l}
32 \\
\end{tabular} & 3 & $4^{+}$ & 5 & $4=$ & $3+$ & 5 & 5 & 5 & 5 & \begin{tabular}{l|l}
5 & 5 \\
\end{tabular} & \begin{tabular}{l|l}
5 & 5 \\
\end{tabular} & 5 & 5 & 5 & 5 & 55 & 5 \\
\hline Exten. Digit. & 0 & 0 & 0 & 0 & 0 & 0 & 0 & 0 & 0. & 0 & 0.10 & 0.0 & 0 & 0 & 0 & 0 & 0 & $0: 1$ & 0,0 & 0 & 10 & 0 & 0 & 2 & 33 & $3+$ & 3 & $3 \mid 4$ & 4 & 5 & $5 \mid 4$ & 4 & $3^{+}$ & 5 & 5 & 5.5 & 5 \\
\hline Flexor. Digit & 0 & 0 & 0 & 0 & 0 & 0 & 0 & 0 & 0 & 0.1 & 010 & 0 & 0 & 0 & 0 & 0 & 0 & 015 & 0 & 0 & 10 & 0 & 0 & 0 & 01 & $1-$ & 1 & 21 & $1+$ & 2 & 23 & 3 & & $4-$ & $\mathrm{K}^{+}$ & $3+4$ & 4 \\
\hline Flexor.Car.UIn & 0 & 0 & 0 & 0 & 0 & 0 & 0 & 0 & 0 & 0 & 010 & 0.0 & 0 & 0 & 0 & 0 & 0 & 0. & 01 & 20 & 0 & 0 & 0 & $2+$ & 4 & 5 & 5 & 45 & 5 & $5 \sqrt{5}$ & \begin{tabular}{l|l}
5 & 5 \\
\end{tabular} & $\begin{array}{ll}5 & 5 \\
\end{array}$ & 4 & 5 & 5 & $5 \sqrt{5}$ & 5 \\
\hline Opponens & 0 & 0 & 0 & 0 & 0 & 0 & o. & 0 & 0 & 0.0 & $0\}$ & 010 & 0 & 0 & 0. & 0 & D) & o. & 010 & 0 & 0 & 0 & 0 & 0 & 0 & 0 & 0 & 0.5 & 0 & $0\}$ & 00 & 0 & 0 & 0 & 0 & 0 & 0 \\
\hline Inter. Lumbri. & 0 & 10 & 0 & 0 & 0 & 01 & 01 & 01 & 01 & 0 & 01 & 010 & 0 & 10 & 0 & 0 & 01 & 01 & 010 & 10 & $\sqrt{0}$ & 0 & 0 & 0 & 01 & 0 & 01 & 0,10 & 0 & 010 & 010 & 010 & 10 & 0 & 4 & & $4+$ \\
\hline
\end{tabular}

Motor tests of 40 upper limbs:

FIG. 6

(I) Each column corresponds to a limb, the limbs are classified according to the lesional level, proceeding downwards.

(2) Each line corresponds to a muscle. The sequence of classification of the muscles is drawn to a large extent from the work of Kendall and that of the British Medical Research Council. The shaded area which covers all the zero grades shows clearly that certain muscles are not placed correctly, such as the extensor carpi radialis and the extensor carpi ulnaris.

cation of muscles, which was worked out by examining the above-mentioned correlations from the qualitative (relevance of the zero gradings) as well as the quantitative standpoint (fig. 7).

I. Biceps-Deltoid. Whereas in our previous classification the deltoid came before the biceps, our observations lead us to think that the nucleus of the biceps is situated somewhat higher. As cases of survival with a biceps or deltoid at zero are rather infrequent because of the proximity of the diaphragm nucleus, our opinion is supported by a very limited number of cases, without zero gradings. A study of recent upper lesions corroborated our feelings that, as a rule, the biceps responds better. This statement, however, should be qualified. We intend to carry on our investigation and see whether we can dissociate the three portions of the deltoid and also the three flexors of the elbow (the brachoradialis is much easier to test separately than the brachialis).

2. Pectoralis. The clinical examination of the lesions of the cervical spinal cord often shows a dissociated pectoralis major, with for instance a good response from the clavicular fibres, a contraction in the sternal fibres and no response at all from the costal portion. We even found lesions with perfectly normal clavicular fibres and costal fibres responding only when in stretching and supplied, in all likelihood, from below the lesion. Although a painful retraction of the upper fibres of the trapezius due to a disequilibrium between the depressors and elevators of the shoulder can prevent the examiner from testing the condition of the lower portion, the risks of error in this test are minimal and it must be possible to carry out a separate study of the three portions of the pectoralis major. The part played by this muscle in the internal rotation is well established and its proximity to the internal rotators should not therefore come as a surprise. 


DELTOID
DELTOID
BICEPS
BICEPS
BICEPS
EXT. ROTATOR
PECT. MAJOR
PECT. MAJOR
PECT. MAJOR
PECT. MAJOR
INT. ROTATOR
LATISSI. DORSI.
LATISSI. DORSI.
EXT. CARPI. RAD.
EXT. CARPI. RAD.
EXT. CARPI. RAD.
EXT. CARPI. RAD.
PRONATOR
EXT. CARPI. ULN.
EXT. CARPI. ULN.
EXT. CARPI. ULN.
TRICEPS
TRICEPS
TRICEPS
FLEX. CARPI. RAD.
FLEX. CARPI. RAD.
EXT. DIGIT.
EXT. DIGIT.
FLEX. DIGIT.
FLEX. DIGIT.
FLEX. DIGIT.
OPPONENS

BICEPS

EXT. ROTATOR

EXT. ROTATOR

EXT. CARPI. RAD.

PECT. MAJOR

INT. ROTATOR

INT. ROTATOR

LATISSI. DORSI.

EXT. CARPI. RAD.

TRICEPS

LATISSI. DORSI.

EXT. CARPI. RAD.

TRICEPS

PRONATOR

EXT. CARPI. ULN.

TRICEPS

FLEX. CARPI. RAD.

TRICEPS

TRICEPS

EXT. DIGIT.

FLEX. DIGIT.

FLEX. CARPI. RAD.

EXT. DIGIT.

FLEX. CARPI. ULN.

EXT. DIGIT.

FLEX. CARPI. ULN.

FLEX. DIGIT.

FLEX. CARPI. ULN.

FLEX. CARPI. ULN. OPPONENS

INTER. LUMBRIC.

INTER. LUMBRIC.

\begin{tabular}{|c|c|c|c|}
\hline$A$ & $B$ & $C$ & \\
\hline 0 & 5 & 9 & \\
\hline I 3 & 3 & 4 & \\
\hline I6 & 2 & 0 & ++ \\
\hline I 8 & 0 & 0 & ++ \\
\hline 22 & I & 0 & ++ \\
\hline IO & 5 & 4 & \\
\hline 2 & 6 & 9 & \\
\hline I7 & I & I & ++ \\
\hline 0 & 6 & I 3 & \\
\hline I7 & I & 0 & ++ \\
\hline 20 & 0 & 0 & ++ \\
\hline 0 & 0 & 24 & ++ \\
\hline 0 & 4 & IO & \\
\hline 20 & 2 & 0 & ++ \\
\hline 25 & 0 & 0 & ++ \\
\hline 23 & 0 & 0 & ++ \\
\hline 22 & $I$ & 0 & ++ \\
\hline I 3 & 2 & 3 & \\
\hline 0 & 0 & I 3 & + \\
\hline 5 & 0 & 4 & \\
\hline I 2 & I & 0 & + \\
\hline 4 & 6 & 2 & \\
\hline I7 & I & 0 & ++ \\
\hline I3 & 0 & I & + \\
\hline I 4 & I & 0 & + \\
\hline IO & 0 & $I$ & \\
\hline I 5 & 0 & 0 & ++ \\
\hline 0 & I & 8 & \\
\hline 0 & 0 & I6 & ++ \\
\hline I 3 & 0 & 0 & + \\
\hline I I & 2 & I & \\
\hline 0 & 0 & 3 & \\
\hline
\end{tabular}

\section{FIG. 7}

Motor correlations (study made according to Figure 6).

A number of muscular couples has been analysed. For each couple three ciphers:

(A) cases when the first muscle is the stronger one;

$(B)$ cases when they are equal;

$(C)$ cases when the second muscle is the stronger one.

The cases in which both muscles are 0 or 5 have been left out. The differences of a plus or minus sign have been neglected. The most significant correlations have been marked with

$$
\text { -.. or }++ \text {. }
$$

3. Extensors of the Wrist. In several instances we observed the single presence of the extensor carpi radialis longus, which, it may be recalled, is the more external of the two muscles. Its nucleus is, therefore, in all likelihood located somewhat above that of the extensor carpi radialis brevis. The extensors carpi radialis are not only, as was said earlier, above the pronators but also above all the forearm muscles (with the probable exception of the brachioradialis). Sometimes one has to test the muscle very attentively, keeping the wrist slightly in extension, to discover the grades I or 2.

4. Triceps-Flexors Carpi Radialis. Their nuclei are, in our opinion, very close together. With regard to the triceps, we might perhaps ask ourselves if, as holds true for the quadriceps, the vasti muscles are not supplied by a somewhat lower innervation. For the time being, we must admit our inability to provide an answer to this question. On the other hand we can point out that in testing the triceps a 
contracture of the biceps keeping the triceps in stretch can interfere with the investigation. Unless attended to, such a contracture occurs at a very early stage in all C6-C7 lesions when the biceps is definitely stronger than the triceps. According to Guttmann (I963) this may even hinder the recovery of the triceps and can thus lead to erroneous conclusions about the level of its nerve supply. Most fortunately, amongst our patients there were too few cases where such a contracture was present for us to consider the elongated condition of the triceps a cause of error.

5. Flexor and Extensor Carpi Ulnaris. These two muscles lie in close proximity but whereas the B.M.R.C. places the extensor carpi ulnaris somewhat higher, on the same level as the triceps, we reached the opinion that the flexor carpi ulnaris was located somewhat above the extensor carpi ulnaris. The latter muscle is practically on a level with the extensor digitorum communis. However, one should proceed with caution when dealing with a limited number of cases and also with muscles where slight contractions may very well pass unnoticed. (Fig. 8).

\begin{tabular}{|c|c|c|c|c|c|c|c|c|c|c|c|c|c|c|c|c|c|c|c|c|c|c|c|c|c|c|c|c|c|c|c|c|c|c|c|c|c|}
\hline & $\begin{array}{l}0 \\
\text { 하 }\end{array}$ & 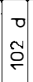 & $\begin{array}{l}0 \\
\cong \\
\end{array}$ & & & & & & & & & & & & & & & $\begin{array}{l}\sigma \\
\circ \\
\text { 의 }\end{array}$ & & $\begin{array}{l}\text { ㅁ } \\
\stackrel{ }{ }\end{array}$ & & & & & & & $\left\{\begin{array}{l}0 \\
\frac{a}{5}\end{array}\right.$ & $\left\{\begin{array}{l}0 \\
F\end{array}\right.$ & & & & & & $\stackrel{0}{F}$ & & & \\
\hline & 4 & 3 & 14 & & $4+$ & 5 & 5 & $4-4$ & & 5 & 5 & 5 & 5 & 55 & 5 & 5 & 5 & 5 & & $4+$ & 5 & $5 \mid 5$ & & 55 & & 5 & 5 & 5 & 5 & & & & & 5 & 5 & 5 & \\
\hline Deltord & $3+$ & $1+$ & $1+$ & 4 & $3+$ & 4 & 4 & 4 & 4 & 4 & 5 & 5 & 5 & 55 & 5 & $5 \longdiv { 4 }$ & 5 & 5 & 4 & 4 & 5 & 5 & 4 & 5 & 5 & 5 & 5 & 5 & 5 & 5 & \begin{tabular}{l|l}
5 & 5 \\
\end{tabular} & $5 \mid 5$ & 5 & 5 & 5 & 5 & \\
\hline Ext. Rotalors & 0 & 1 & 3 & 4 & 41 & 1 & 1 & 3 & 3 & 4 & 4 & 4 & -3 & -4 & 5 & 5 & $4+$ & 5 & $3+$ & $3+$ & 5 & 5 & 5 & 5 & 5.5 & 5 & 5 & 5 & 5 & 5 & 55 & 55 & 5 & 5 & 5 & 5 & \\
\hline Exlen. Carp Rad & 0 & 0 & 0 & 1 & 1 & 2 & 2 & 3 & $3+$ & $3^{+}$ & 4 & 44 & + & 45 & 55 & 54 & +5 & 5 & 4- & $4-$ & 5 & 54 & & 5 & $5 \sqrt{5}$ & 5 & 5 & 5 & 5 & 5 & 5 & 5 & 5 & 5 & 5 & 5 & \\
\hline Int. Rotators & 0 & 1 & $2+$ & 0 & 0 & 0 & 0 & 0 & 0 & 4 & 4 & 43 & +3 & +4 & $4+4 t$ & +5 & 3 & 3 & 4 & 4 & 5 & 5 & 5 & 5 & 55 & 5 & 5 & 5 & 5 & 5 & \begin{tabular}{l|l}
5 & 5 \\
\end{tabular} & 5 & 5 & 5 & 5 & 5 & 5 \\
\hline Pect.Maior & 0 & 0 & 0 & a & 0 & 0 & 0 & 0 & 0 & $2+$ & 4 & 4 & $4-1$ & $3 \sqrt{3}$ & $3+4$ & $4-4+$ & +4 & $3+$ & $4-$ & 4 & 5 & 54 & + & 5 & 5.3 & 5 & 5 & 5 & 5 & 5 & & + & 5 & 5 & 5 & 5 & \\
\hline Pronators & 0 & 0 & 0 & 0 & 0 & () & 0 & 0 & 0 & $2+$ & 0 & 0 & 3 & $3 \sqrt{3}$ & $3-4$ & -4 & 3 & $2+$ & $3+$ & $3+4$ & $4+$ & 5 & 4 & 55 & 54 & 5 & 5 & 4 & 5 & 5 & 55 & 5 & 5 & 5 & 5 & 5 & 5 \\
\hline Trice & 0 & 0 & 0 & 0 & 0 & D) & 0 & 0 & 0 & 0 & 1 & 1 & 0 & o) & 0,0 & 010 & 2 & $+2+$ & 3. & 32 & $2=$ & $3-\sqrt{3}$ & $3+$ & 54 & +3 & 5 & 5 & 5 & 5 & 5 & 5 & 5 & 5 & 5 & 5 & 5 & 5 \\
\hline Fle & 0 & 0 & 0 & 0 & 0 & 0 & 0 & 0 & 0 & 0 & 0 & 0 & 0 & 0 & 0 & 0.1 & 10 & 0 & 3 & 3 & 2 & 34 & + & 54 & 43 & 5 & 5 & 5 & 5 & 5 & 5 & 5 & 5 & 5 & 5 & 5 & 5 \\
\hline Lakissi. Doiri. & 0 & 0 & 0 & 0 & 0 & 0 & 0 & 0 & 0 & 0 & 0 & 1 & 0 & 0,0 & 0 & $\begin{array}{lll}0 & 0 \\
\end{array}$ & 0 & 0 & 0 & 0 & 1 & $1+$ & 3 & 5 & $4: 3$ & 5 & 5 & 5 & & $4^{+}$ & 5 & 5 & 5 & 5 & 5 & 4 & \\
\hline Flexor. Car. Ulina. & 0 & 0 & 0 & 0 & 0 & 0 & 0 & 0 & 0 & 0 & 0 & 0 & 0 & 0 & 0.0 & 0.0 & 0 & 0 & 0 & 2 & 0 & 0 & 010 & 02 & +4 & 5 & 5 & 4 & 5 & 5 & 5 & 5 & 4 & 5 & 5 & \begin{tabular}{|l|}
5 \\
\end{tabular} & 5 \\
\hline Exte & 0 & 0 & 0 & 0 & 0 & 0 & 0 & 0 & 0 & 0. & 0 & 0 & 0 & 0 & 0.0 & $0: 0$ & 0 & 0 & 0 & 0 & 0 & 0 & 0 & 0 & 2 & $3 \sqrt{3}$ & 3 & 3 & 4 & 5 & 5. & 4 & 5 & +5 & 5 & 5 & \\
\hline Exten.Car.Ülna. & 0 & 0 & 0 & 0 & 0 & 0 & 0 & 0 & 0 & 0 & 0 & 0 & 0 & 0 & 0 & 010 & 0 & 0 & 0 & 0 & 0 & 0 & 0 & 0 & 0.0 & 5 & 5 & 2 & 5 & 5 & 5 & 5 & 5 & 5 & 5 & & \\
\hline Flexor. Digit. & 0 & 0 & 0 & 0 & 0 & 0 & 0 & 0 & 0 & 0 & 0 & \begin{tabular}{l|l}
0 & 0 \\
\end{tabular} & 0 & 0 & 0 & 0.0 & 5 & 0 & 0 & 0 & 0 & 0 & 0 & 0 & 00 & 1. & 1 & 2 & $1+$ & 2 & 2 & 3 & & +4 & $4+$ & $3+$ & \\
\hline Inter. Lumbri. & 0 & 0 & 0 & 0 & 0 & 0 & 0 & 0 & 요 & 0 & 0 & 0 & 0 & 0 & 0,0 & 00 & $\sqrt{0}$ & 0 & 0 & 0 & 0 & 01 & 0 & 0 & 05 & 50 & 10 & 0 & 0 & 0 & 0 & 0 & 10 & 10 & 4 & 4 & \\
\hline Opponens & 0 & 10 & 0 & 0 & 01 & 01 & 0 & 0 & of & 0 & $0 \mid$ & 0,0 & 0 & 0 & 010 & 010 & 10 & 0 & 0 & 0 & 0 & 01 & 0 & 0 & 010 & 0 & 10 & 10 & 10 & 0 & 010 & 0 & 10 & 10 & 10 & 0 & 0 \\
\hline
\end{tabular}

FIG. 8

Motor testings of 40 upper limbs with new classification of muscles (according to the result of comparisons by groups of two). The shaded area which covers all the zeros throws the regular appearance of positive gradings into relief as the lesional level becomes lower and lower.

6. Hand. Our clinical impressions have already been thoroughly confirmed by the evidence that our chart of gradings provides the respective positions of the three main muscle groups, placed in the following downward sequence: extensors, flexors, interossei-lumbricals (one should stress the frequency of lower cervical lesions with the extensor digitorum communis as the sole motor potentiality left to the hand). But, availing ourselves of the fact that of the 40 limbs there were I 6 hands which had retained the use of one or several muscles, we decided to study them more thoroughly and reached a number of conclusions:

(a) Of all the muscles of the hand, the extensor digitorum communis is, in our opinion, the one located the highest, the opponens the lowest.

(b) The flexor digitorum sublimis seems to be above the flexor digitorum profundus; their respective grades may prove difficult to determine when both 
muscles respond, but when the middle phalanx and not the distal phalanx responds, there can be no doubt about the flexor digitorum profundus being at zero.

(c) As in most cases the performance of the flexor digitorum profundus and sublimis showed a steady decrease from the 5 th to the 2 nd, it may be inferred that the highest nucleus is that of the 5 th and the lowest that of the 2 nd.

For the thumb, the uppermost muscle seems to be the extensor pollicis brevis. It would seem unjustified to proceed further, considering the hazards involved in the testing of a hand and the many risks of error encountered when investigating the nuclei, most probably extremely small, of some I5 muscles, all clustered within the space of one or two cord segments.

This observation shows the limits of our study. We might have included a number of other muscles of the upper limb and, in particular, those which might be of great functional value: lower fibres of the trapezius, pectoralis minor, teres major which, in our opinion, is the first depressor to arise after the lower portion of the trapezius. But as we were reluctant to introduce mere approximations into our study when dealing with muscles or fibres which are difficult to measure precisely, we preferred, at this initial stage of our work, to restrict ourselves to simple data where the margin of error would be minimal.

Actually, the key-muscles of the upper limb are very limited in number and the functional prognosis of a complete cervical lesion is chiefly conditioned by three muscles or muscle groups:

The flexors of the elbow which enable a patient to feed himself, to operate a page-turner or an electric wheel-chair.

The extensor carpi radialis with which a patient may handle a wheelchair, write and, not infrequently, retain a certain degree of passive grasping.

The triceps and the depressors of the shoulder which, more than any other muscles, are indispensable, for moving from the bed to the wheelchair and, more generally, for enabling a certain degree of independence when seated.

When a certain degree of strength is present in the above-mentioned muscles, we are inclined to think that the lesion occurred below $\mathrm{C}_{5}, \mathrm{C}_{6}$ and $\mathrm{C}_{7}$ respectively, as can be assumed from an examination of Figure 9.

The figure shows that the biceps begin at segment $\mathrm{C}_{5}$, immediately followed by the deltoid. The external rotators come next, with the extensors carpi radialis, the longus occurring somewhere before the extensor carpi radialis brevis.

To segment C6 correspond the upper levels of the nuclei of the internal rotators, the pectoralis major, the pronators and perhaps those of the triceps and flexors carpi radialis, which, in our opinion, lie in close proximity and start at the conjunction of $\mathrm{C} 6$ and $\mathrm{C}_{7}$.

The latissimus dorsi and the flexor carpi ulnaris occur on the latter segment, followed by the extensor digitorum communis and the extensor carpi ulnaris, almost on the same level. Finally, the last two segments correspond exclusively to the upper levels of the motor nuclei of the hand in the following order: flexors (with the flexor digitorum sublimis coming first), interossei-lumbricals, opponens muscles. 


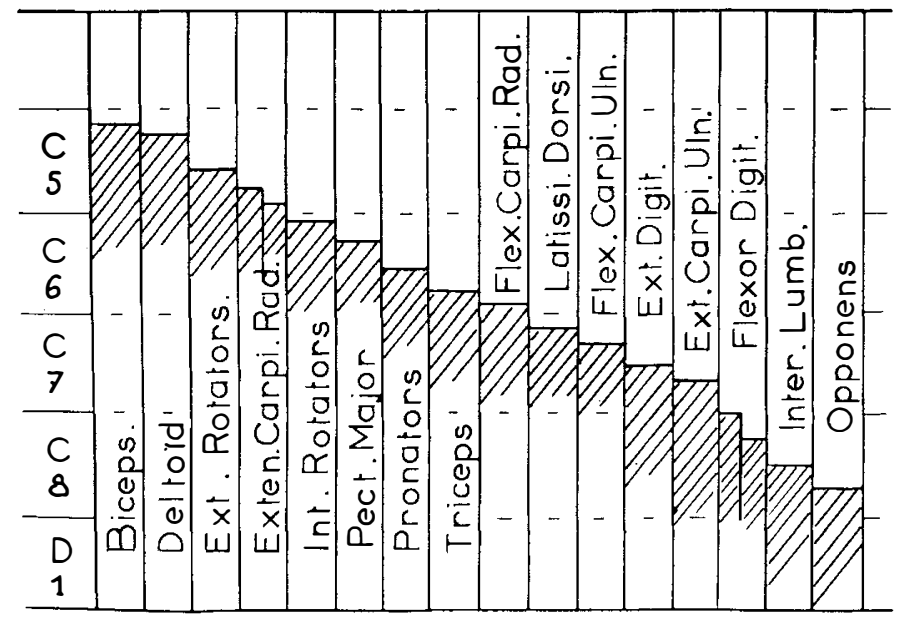

FIG. 9

Upper limits of the various certival myotomes. The segmental references are indicated here in a hypothetical way. The purpose of this chart is to show how, from our experience, the upper levels of the myotomes seem to follow one another in the motor organisation of the spinal cord and cervical roots. One will moreover find in the text reservations we consider as necessary for this.

\section{DISCUSSION}

As our investigation could not lead to a determination of the precise height of the nuclei, we were solely concerned with the sequence in which the upper levels of the motor nuclei followed one another within the spinal cord. The segmental references given in Figures 4 and 9 are thus purely hypothetical and to a large extent they reflect current opinions on the subject. Although it is difficult, perhaps impossible, when studying such a problem, to discriminate between what pertains to the spinal cord and what pertains to the roots in paraplegia, it is above all the spinal cord which has been the subject of our investigation. Hence we feel justified in assuming the existence of different levels, whereas such a method of approach might seem too ingenious if applied to the roots. It seems indeed rather impracticable to differentiate topographical levels on a spinal root, but such a procedure is perfectly appropriate when dealing with a cord segment.

The relevance of such a segmental approach may appear disputable if one bears in mind that between the various segments of the spinal cord there exist highly diversified connections, that the cord segment is not an anatomical unit, that the spinal root has probably no more than a distributive function, and that from one individual to another variations are found, limited though they may be. Actually, the clinician with a daily experience of such lesions is not interested in the metamerical arrangement from a theoretical standpoint only; this approach also provides him with a common terminology for lesions indicating level of lesion (a letter followed by a number) which offers a comprehensive view of neurological 
damages. With some practice, the clinician will recognise immediately the motor condition of his patient and give the functional prognosis for a $\mathrm{L}_{4}$ paraplegia or a $\mathrm{C}_{7}$ tetraplegia. (Although convenient, this use of symbols for denoting lesions still leads to a certain degree of inaccuracy. The muscle testing of a patient may show a slight difference between the two extremities without there being any disparity in terms of segments and we would often like to qualify our symbols with a plus or minus sign as in grading muscles.)

Thus, it is encouraging that there should be but little discrepancy between our findings and the ideas commonly held on the subject. As our approach is very special, we readily admit that certain aspects of it are open to criticism. Moreover, it should be stressed that our results are only approximate. There is, in muscle testing as in any other method of measurement depending wholly upon human judgment, a certain degree of subjectivity that cannot be ignored. However, this factor may prove quite negligible if the testing is carried out by one or several skilled examiners. Furthermore, one should not ignore either the rare though real possibility of initially weak muscles retrograding from I or 2 to zero, through inaction in cases where the lesion is not recent.

Another debatable point is whether the same argumentation and deductions apply equally to muscles, such as the pectoralis major and the quadriceps, whose nuclei spread along three or four segments and to muscles such as the opponens and the tibialis anterior whose nuclei are more or less confined to the limits of a single segment. (In this connection, after observing that certain muscles appeared on our chart with immediately high grades, we asked ourselves whether the evidence of large numbers might not demonstrate that their nuclei are short.)

Our study may be criticised for not providing any data on the lower level of the nucleus. One possible hypothesis would be that it is reached when grades 5, corresponding to a so-called normal performance, appear. Actually, as was said earlier, the idea of 'normal' performance is open to debate since grade 5 is far from corresponding invariably to an intact nucleus. The use of dynamometer measurements of certain muscles such as the triceps brachialis or the quadriceps might lead to a more accurate estimation of whether or not a muscle performance is normal. However, the best approach to determine the origin of the lower level of the motor nuclei for the time being would appear to be a study of suspended segmental or multi-radicular lesions, which would be well worth undertaking.

We hope that in spite of such reservations this study may contribute to the knowledge of the metamerical arrangement of the motor cells corresponding to the extremities. We intend to go further than this preliminary stage but now we are at least in possession of a scheme, derived from our clinical experience, which will prove a useful instrument in our work.

\section{SUMMARY}

The authors have collaborated in studying the segmental innervation of the muscles in spinal injuries.

They begin by reviewing the historical aspects of this systematisation, which is still uncertain, and continue by describing their methods of investigation on complete and stabilised spinal cord lesions, in all of which muscle charts have been made.

By classifying all these tests in decreasing segmental levels, their comparison allows one to see in which order the muscles appear as the level of innervation 
descends. It seems obvious that in a series of quotations corresponding to a muscle the change from several zeros to one or two bears some relation to the upper segmental innervation of that muscle.

The main muscles of the upper and lower limbs have been studied and compared two by two. The authors submit a chart for the upper segmental innervation of the studied muscles.

They draw attention to the reasons for errors in muscle testing and discuss the reservations which must be made in respect of their work.

\section{RÉSUMÉ}

Les auteurs ont conjugué leurs efforts pour étudier la systématisation motrice à partir des lésions de la moelle épinière.

Après avoir rappelé l'historique de cette systématisation, qui comporte encore des imprécisions, ils exposent leur méthode de travail, sur des lésions complètes et stabilisées, qui ont toutes des bilans musculaires.

Le classement de tous ces bilans par niveau lésionnel décroissant et leur comparaison permet de voir l'ordre dans lequel apparaissent les muscles, à mesure que s'abaisse le niveau lésionnel. Et il parait évident que, dans la série des cotations correspondant à un muscle, le passage d'une suite de zéros aux cotes I ou 2 n'est pas sans rapport avec le niveau supérieur du noyau du muscle intéressé.

Les principaux muscles du membre inférieur et du membre supérieur ayant été ainsi étudiés puis comparés 2 par 2 , les auteurs proposent une nouvelle carte métamérique des niveaux supérieurs des noyaux moteurs.

Enfin ils rappellent les causes d'erreur, en particulier dans les bilans musculaires, et discutent les réserves qu'ils estiment nécessaire de faire sur leur travail.

\section{ZUSAMMENFASSUNG}

Die Autoren haben in einer gemeinsamen Arbeit die segmentale Innervation der motorischen Spinalkerne nach Rueckenmarksverletzungen untersucht.

Nach einem historischen Ueberblick dieser Systematisierung beschreiben sie ihre eigene Arbeitsmethode an completten stabilisierten Querschnittslaesionen, in denen Muskelfunktionspruefungen in Muskelkarten niedergelegt waren.

Die Einteilung dieser Muskelkarten entsprechend abnehmender Muskelfunktion und deren Vergleich erlaubt eine Einordnung, in welcher die einzelnen Muskeln erscheinen, je nachdem der Grad der Schaedigung abnimmt. Die Einteilung der Funktionswerte von null bis eins oder zwei laesst eine segmentale Hoehenbestimmung einzelner Muskeln zu.

Nach dem die Autoren vergleichende Untersuchungen der oberen und unteren Extremitaet angestellt haben, schlagen sie eine 'carte metamerique' fuer die obere segmentale Innervation der untersuchten Muskeln vor.

Schliesslich weisen sie selbst auf die Ursachen von Irrtuemern in den Muskelfunktions. karten hin und diskutieren die Vorbehalte welche ihre Arbeit erfordert. 


\section{REFERENCES}

Benassy, J. (1963). Int. F. Paraplegia, I, 70.

BenNett, R. L. (I95I). Physical Medicine in Poliomyelitis. Points of Emphasis, Poliomyelitis Papers and Discussions presented at the second international poliomyelitis conference, p. 26I. Philadelphia: Lippincott.

BERT, P. (1883). Histoire naturelle-Anatomie et physiologie animales. Paris: Masson.

BRUCE, A. (I90I). A Topographical Atlas of the Spinal Cord. London: Williams and Norgate.

Decoulx, P., Rasemon, J. P., Lemerle, P., \& Waghemacker, R. (I96I). Sciatique paralysante. Etude pathogénique. Ann. Chir., pp. 23-24.

Dejerine, J. (I9I4-26). Seméiologie des affections du système nerveux. Paris: Masson.

Delmas, J., \& Delmas, A. (1948). Voies et centres nerveux. Paris: Masson.

FERRIER, D., \& YEO, G. F. (I88I). The functional relations of the motor roots of the brachial and lumbosacral plexuses. Proc. R. Soc., 32, I2.

Foerster, O. (1929). Spezielle Anatomie und Physiologie der Peripheren Nerven, Handbuch der Neurologie, p. 946.

Foerster, O. (1936). Handbuch der Neurologic, vol. 5, pp. I20-I27. Berlin: J. Springer.

Grasset, J., \& RAUZIER, G. (1894). Traité Pratique des Maladies du système nerveux. Paris: Masson éd.

Guttmann, L. (1963). Int. F. Paraplegia, I, 7 I.

Holdsworth, F. W., \& Hardy, A. (I953). F. Bone ft. Surg., 35B, 540.

Kendall, H. O., \& Kendall, F. P. (I949). Muscle Testing and Function. Baltimore: Williams and Wilkins Company.

LaSt, R. J. (I949). F. Bone ft. Surg., 3IB, 452.

MAURY, M. (I956). 'La rééducation des Paraplégiques. Bilan des lésions-PrincipesDifficultés-Résultats.' Rev. Prat. (Parc), 6, I754.

Medical Research Council (M.R.C.) (I943-60). Aids to the Investigation of Peripheral Nerve Injuries. War Memorandum No. 7. London: H.M. Stationery Office.

Merle D’Aubigne, R., Benassy, J., \& Ramadier, J. (I956). Chirurgie orthopédique des paralysés. Paris: Masson.

MorIN, G. (I948). Physiologie du système nerveux central. Paris: Masson.

PURVes-STEwaRT, J. (1939). Diagnostic des maladies nerveuses (adapté et annoté par Laruelle). Paris: Doin.

Ribet, R. M. (1957). Systematisation des Centres nerveux et de leurs connexions. Constitution du névraxe, voies centrales et périphériques. Paris: Doin.

Romanes, G. J. (I94I). F. Anat. (Lond.), 75, I45.

RoMANES, G. J. (I94I). F. Anat. (Lond.), 76, I 12.

Romanes, G. J. (I94I). F. Anat. (Lond.), 77, I.

Romanes, G. J. (1946). F. Anat. (Lond.), 80, i 17.

Romanes, G. J. (1953). Ciba Symp., pp. 24-42. J. and A. Churchill, London.

SANo (1897). Les localisations motrices dans la moëlle épinière. Premier congrés international de neurologie, Bruxelles. p. 37.

SANo (1897). F. Neurol. (Brux.), I, 354.

Schliak von Hans (I957). Disch. med. Wedn., 43, p. I820.

SharraRd, W. J. W. (I955). F. Bone ft. Surg., 37B, 540.

SHERrington, C. (Sir) (I892). F. Physiol. 13,621.

SHERRINGTON, C. (1939). Selected writings of Sir Charles Sherrington. A testimonial presented by the neurologists of the journal Brain (compiled and edited by Denny Brown). London: Hamilton.

Van GehuChten, A., \& DE BuCK (1898). F. Neurol. (Brux.), 2, 48.

Van Gehuchten, A., \& De Neef (1900). Névraxe, I, 201.

VILLIGER \& LudWIG (1946). Die periphere innervation. Bâle. 